\title{
Performance of a Nonwoven Geotextile Reinforced Wall with Unsaturated Fine Backfill Soil
}

\author{
Fernando Henrique Martins Portelinha ${ }^{1}$, Benedito de Souza Bueno ${ }^{2}$ and Jorge Gabriel Zornberg ${ }^{3}$ \\ 1. Department of Civil Engineering, Federal University of Sao Carlos, Sao Carlos/SP 13564-350, Brazil \\ 2. Sao Carlos Engineering School, University of Sao Paulo, Sao Carlos/SP 13566-536, Brazil \\ 3. Civil Engineering Department, University of Texas at Austin, Austin/TX 78712-0280, USA
}

\begin{abstract}
The use of marginal backfills in GSE (geosynthetic stabilized earth) walls has not been recommended by different standards specifications. Restrictions are motivated by the poor hydraulic conductivity of fine soils that are capable of developing of water pressures. However, the use of granular materials can expend the cost of the construction. As a result, local soils, granular or not, have been increasingly used. Unsaturated conditions of fine soils may result in convenient performance even using extensible reinforcements. This paper evaluates the performance of a full scale model of a nonwoven geotextile reinforced wall constructed with fine grained soil backfill. The unsaturated condition was maintained and matric suctions, displacements and reinforcement strains were monitored during the test. Results have shown that the unsaturated condition of the backfill allowed maximum reinforcement peak strain of $0.4 \%$. For the case of a wrap faced wall on a firm foundation the performance and good agreement between measured strains and factors of safety from limit equilibrium analyses have shown the maintenance of unsaturated conditions as an economical alternative to the use of high quality fill.
\end{abstract}

Key words: Reinforced soil wall, nonwoven geotextile, fine soil, unsaturated soil.

\section{Introduction}

Since the reinforced soil technique began to be used in retaining walls, embankments and slopes, standard organizations have been concerned about the hydraulic behavior of poorly draining backfill soils $[1,2]$. The major problems are the development of positive water pressures inside the reinforced zone and reinforcement interaction in the presence of water.

In fact, the low draining capacity of fine soils can affect the reinforced soil walls performance under rainfall infiltration as reported by Yoo and Jung [3] and Fowze et al. [4]. On the other hand, an excellent performance can be expected from these structures under unsaturated conditions due to the positive effect of matric suction on soil and interface behavior. Khoury et al. [5] report that pullout strength of

Corresponding author: Fernando Henrique Martins Portelinha, Ph.D., research fields: development of concepts, methodologies and tools focused at the geosynthetic technologies applied to geotechnical engineering. E-mail: fportelinha@gmail.com. geotextiles embedded in unsaturated soils are so influenced by matric suction as shear strength of soils. Additionally, some real cases reported in the literature could confirm the strong influence of unsaturated conditions of backfill on the performance of geosynthetic reinforced soil walls $[6,7]$. The maintenance of unsaturated conditions of backfill soils is a difficult task regarding field conditions. Koerner and Soong [8] recommend avoiding any possible water in the front, behind and beneath the reinforced zone collecting, transmitting and discharging the water. Furthermore, the top of the zone should be waterproofed, e.g., by a geomembrane or a geosynthetic clay liner, to prevent water from entering the backfill zone from the surface. However, Wayne and Wilcosky [9] reported that use of nonwoven geotextiles assisted in maintaining fine grained soils in an unsaturated condition in the reconstruction of failed slope, since the hydraulic properties of nonwoven geotextile reinforcements can be useful to 
dissipate pore water pressures and, consequently, enhance the internal stability of the structure $[10,11]$.

Matric suction can improve the walls performance in two aspects: increasing the soil stiffness and improving the interface shear strength behavior. Therefore, two design implications can be drawn from these aspects: a stiffer soil favors the selection of lower stiffness reinforcements, resulting in reductions of costs; and, convenient interface behavior provides a good transmission and mobilization of forces by the reinforcement.

This paper describes the performance of an instrumented full scale model of a nonwoven geotextile reinforced soil wall under unsaturated backfill conditions.

\section{Experimental Program}

\subsection{Materials}

Full scale models were constructed using clayey sand with a hydraulic conductivity of $5 \times 10-6 \mathrm{~cm} / \mathrm{s}$, with $40 \%$ passing the No. 200 sieve, and low plasticity $(\mathrm{PI}=18 \%)$. Compaction parameters from standard Proctor tests are maximum dry unit weight of $17.8 \mathrm{kN} / \mathrm{m}^{3}$ and optimum water content of $14.6 \%$. With the relative low hydraulic conductivity and significant percentages of fine particles, this material would be restricted from use by AASHTO [2] and FHWA [1], being classified as a poorly draining soil. Triaxial tests in unsaturated soil samples indicated cohesion of $0 \mathrm{kPa}$ and friction angle of $38^{\circ}$ for $\mathrm{CD}$ (consolidated drained) tests and, cohesion of $60 \mathrm{kPa}$ and friction angle of $25^{\circ}$ for $\mathrm{CU}$ (consolidated undrained) tests, in terms of total stresses.

The reinforcement consisted of a polyester needle-punched nonwoven geotextile made of polyester with a mass per unit area of $293 \mathrm{~g} / \mathrm{m}^{2}$, thickness of $2.69 \mathrm{~mm}$, tensile strength of $10 \mathrm{kN} / \mathrm{m}$ and strain at failure of $83 \%$ (testing was performed in accordance with ASTM D4595). A relatively weak and extensible geotextile was specifically selected to generate detectable strain levels.

\subsection{Full Scale Model Construction}

Full scale walls have been constructed in the Laboratory of Geosynthetics located within the Sao Carlos School of Engineering at the University of Sao Paulo. A metallic box allows reinforced soil wall structures to be constructed with $1.8 \mathrm{~m}$ height by 1.55 $\mathrm{m}$ width, with backfill soil extending to a distance of $1.8 \mathrm{~m}$ from the front edge of the metallic box. The soil was compacted at $98 \%$ of relative density and the maximum dry unit weight and optimum water content from standard Proctor tests. In order to assure the required relative density, compaction was performed manually in layers of $5 \mathrm{~cm}$ height. Compaction control was assured by the drive-cylinder method (ASTM D2937), spiked every compacted layer reaching $30 \mathrm{~cm}$ height. The backfill soil was seated on a rigid concrete foundation.

Geotextile reinforcements were placed at $30 \mathrm{~cm}$ vertical spacing with declivity of $1 \%$ to the face. Each layer of reinforcement had a total length of $1.80 \mathrm{~m}$ measured from the face. The wall was constructed with no facing batter and using the wrapped-around technique. Protective shotcrete coating varying from 5 $\mathrm{cm}$ to $8 \mathrm{~cm}$ was used. Drainage geocomposites were used as face drainage elements into the second and forth reinforced layers located at $30 \mathrm{~cm}$ from the face forward into the wall. Fig. 1 presents the cross section view of the model.

\subsection{Instrumentation}

Instrumentation was deployed to record pore water pressures including negatives values (soil suction), internal horizontal displacements, reinforcement strains and horizontal face displacements. Instruments locations are presented in Fig. 2.

Matric suction was monitored by tensiometers (range of $-100 \mathrm{kPa}$ to $100 \mathrm{kPa}$ ) located in the middle of each reinforced layer at $5 \mathrm{~cm}$ above the reinforcements at a distance of $80 \mathrm{~cm}$ and $140 \mathrm{~cm}$ from the face. 


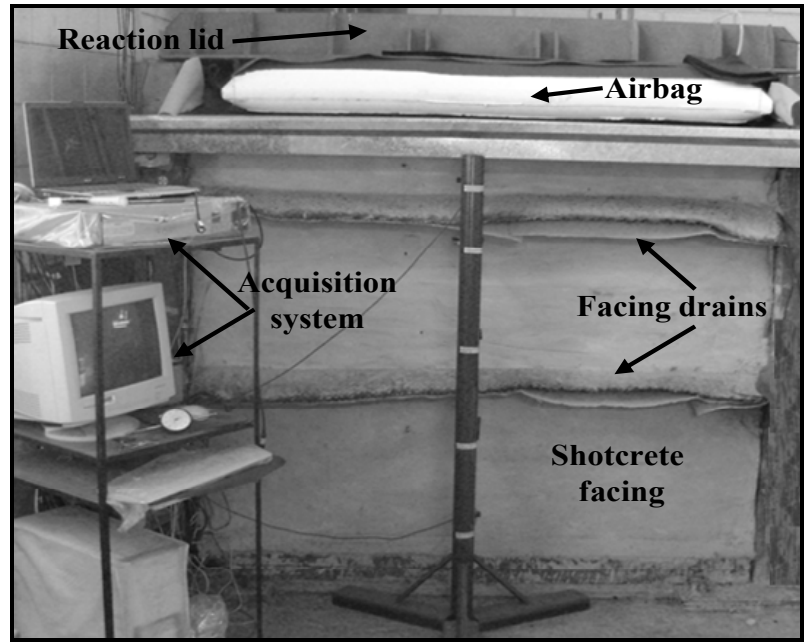

(a) Frontal photograph

Fig. 1 Geotextile reinforced soil wall model.

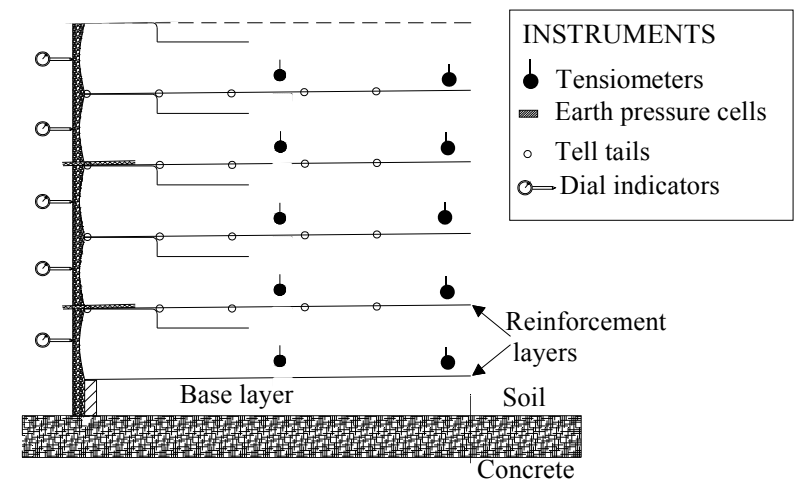

Fig. 2 Instruments location.

Internal displacements were measured by tell-tales. These devices consisted of stainless steel inextensible wires, which run inside of plastic tubes used to reduce friction and to protect the wires. One end of the tell-tales is fixed to the geotextile and the opposite is connected to a small weight that is used to tension the wires and to obtain measures. Relative displacements between the weight and a reference located in a shaft behind the wall were measured during the test. Tell-tales were fixed at five points along reinforcements at $30 \mathrm{~cm}$ of horizontal spacing.

Other displacement instruments were used in this research but they will not be assessed in this paper.

\subsection{Test Procedure}

The test procedure involved recording of instrumentation incorporated within the full scale

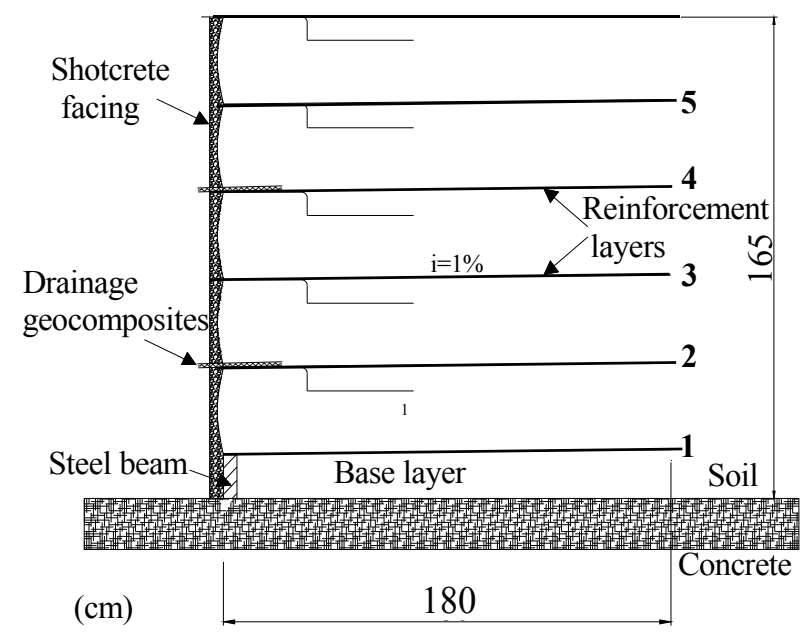

(b) Cross section

model under a uniform loading of $100 \mathrm{kPa}$. Instrumentation records were maintained from the beginning of construction and throughout the initial 90 days of loading.

\section{Results}

\subsection{Instrumentation Results}

Fig. 3 presents results from tensiometers installed at $80 \mathrm{~cm}$ and $140 \mathrm{~cm}$ from the face in each instrumented layer of the model. In general, the initial matric suctions of soil were similar for all reinforced layers and increases of matric suction were observed with time. Higher rates of matric suction increasing occurred in the lower layers, with values varying from $20 \mathrm{kPa}$ to $80 \mathrm{kPa}$. In higher layers, matric suction values ranged from $20 \mathrm{kPa}$ to $30 \mathrm{kPa}$.

Internal displacements measured by tell-tales with time are shown in Fig. 4. This figure presents readings in points located at $0 \mathrm{~cm}, 30 \mathrm{~cm}, 60 \mathrm{~cm}, 90 \mathrm{~cm}, 120$ $\mathrm{cm}$ and $150 \mathrm{~cm}$ from the wall face. Clearly, higher rates of displacement increases occurred as soon as the loading of $100 \mathrm{kPa}$ was applied to the top of the wall. Thereafter, small increases could be evidenced with time. In the reinforced layer 2, displacements were practically constants throughout loading.

Possibly, high values of matric suction of soil during the wall life avoided reinforcement creep strains, 


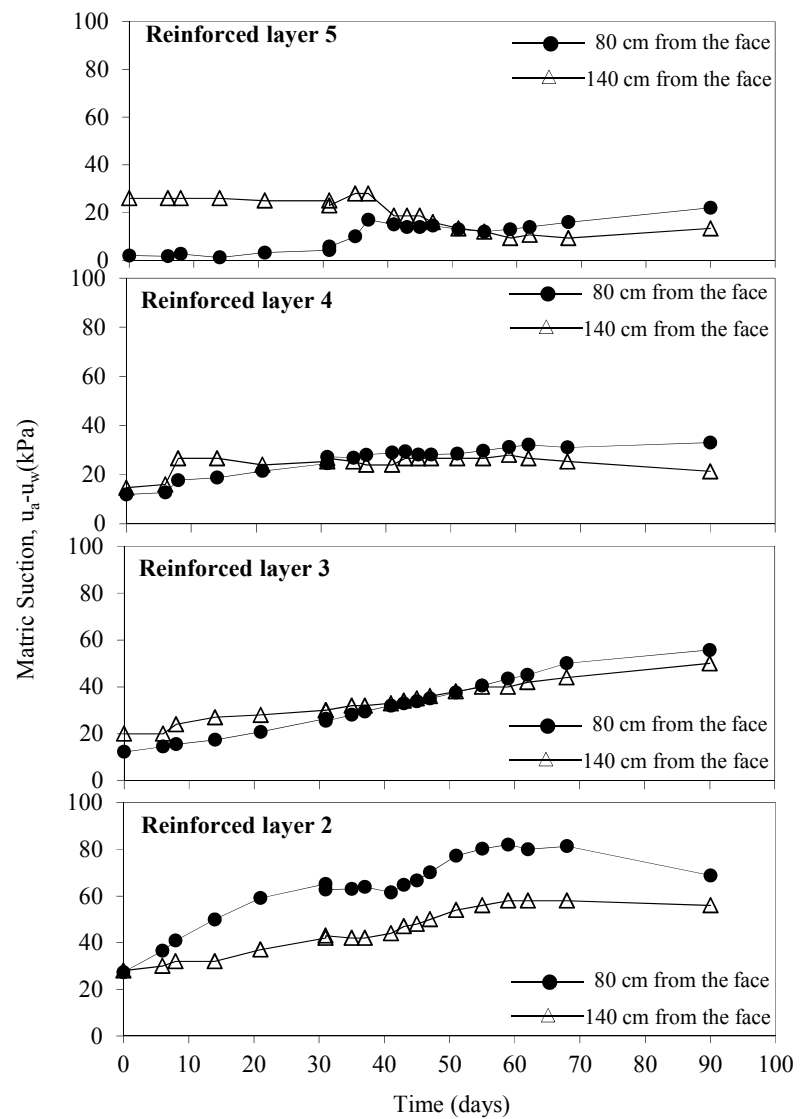

Fig. 3 Matric suction measured by tensiometers with time at $80 \mathrm{~cm}$ and $140 \mathrm{~cm}$ from the wall face.

resulting in a relatively rigid structure. This was substantiated due to the presence of the concrete foundation which limits deformation to the reinforced zone of the structure.

\subsection{Strains in the Geotextiles}

Reinforcement strains were obtained from the relative horizontal displacements between facing and tell-tales attached along the reinforcement length at different distances. The distribution of relative displacement along the reinforcement between points of measurements and wall facing in the reinforced layer 2 is presented in Fig. 5. In this figure, sigmoidal curves fitting the raw data are drawn in order to have a smooth representation of the distribution of displacements along the reinforcement length.

The sigmoidal fitting shown in Fig. 5 was also used to evaluate the distribution of strains along the reinforcement as presented by Zornberg and Arriaga

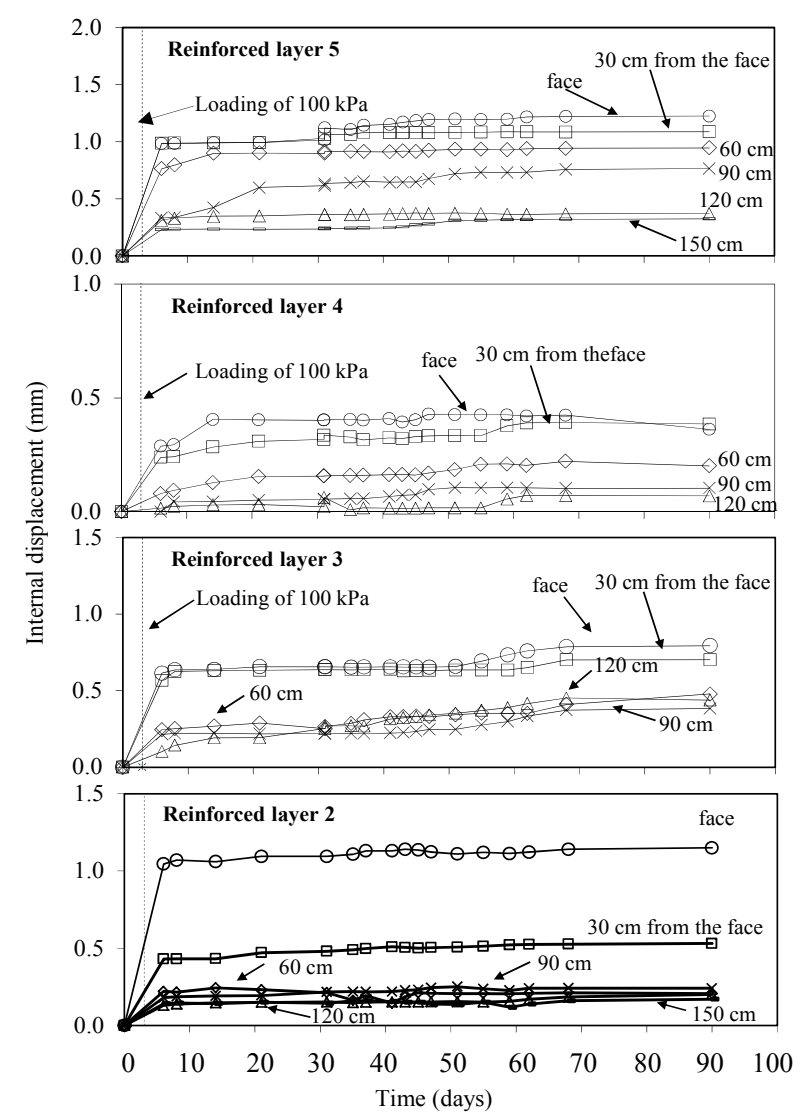

Fig. 4 Internal displacements versus time.

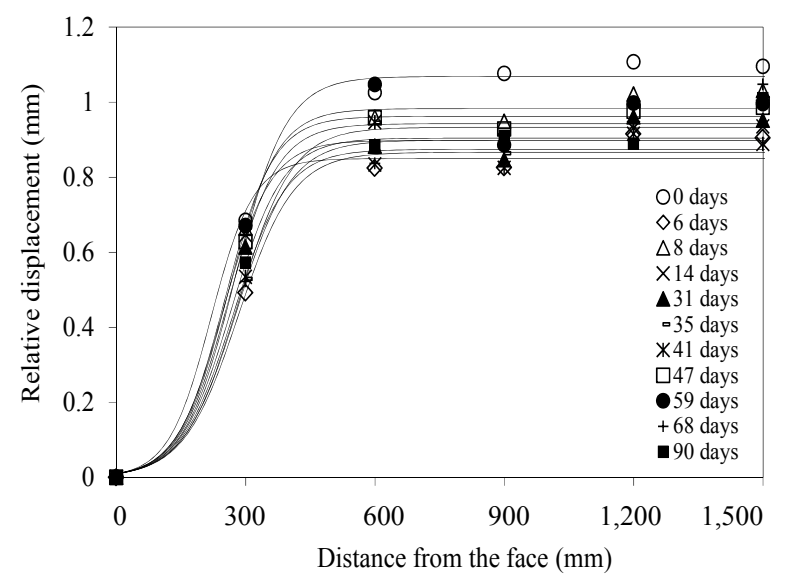

Fig. 5 Distribution of relative displacements between tell tales and wall face along the geotextile length.

[12]. Geotextile strains values can be obtained by calculating relative movements between points of tell tales at different distance from the reference and dividing them by the initial distance between rods.

However, the use of this technique may not be efficient in this case, since the distance between measured points may not be small enough to get a real 
strain between points. For this reason, the raw data from tell tales was initially smoothed by fitting the data to a sigmoidal curve. Thus, the distribution of strains along the geotextile length could be obtained by deriving the displacement function as:

$$
\varepsilon=d\left(\frac{1}{a+b e^{-c x}}\right) / d x
$$

where, $d$ is the tell-tale displacement, $x$ is the distance from the wall face to the measured point, and $a, b$ and $c$ are parameters defined by the fitting of sigmoidal curves to the raw data using the minimum squares technique. This technique was used in a GSE field case by Zornberg et al. [13].

The distribution of strains in each instrumented layer is shown in Fig. 6. The strain levels were very small with a maximum value of $0.43 \%$ in the reinforced layer 2 and minimum value of $0.15 \%$ in the reinforced layer 4. Additionally, no relaxation or retraction of reinforcements could be observed.

A consistent distribution of strains was obtained by the derivation of a sigmoidal fitting curve and a Rankine failure surface seems to properly fit it, assuming a friction angle from $\mathrm{C}-\mathrm{U}$ triaxial tests on unsaturated samples.

The effect of matric suction on the stiffness of soil can be a good explanation for very small strains and displacements even using extensible reinforcements as nonwoven geotextiles. Additionally, interface shear behavior is absolutely improved under unsaturated conditions [5]. Other aspects requiring further consideration is the tensile and creep behavior of nonwoven geotextiles under confined conditions [14]. These influences are not discussed as part of this paper as they are covered in detail elsewhere [1].

\subsection{Limit Equilibrium Analysis}

Factors of safety were calculated by limit equilibrium analyses in order to compare design parameters and measured values. Limit equilibrium analyses were conducted using the technical software UTEXAS3 from the University of Texas, by Wright
[15]. This software allows for analysis of slopes and walls considering the reinforcement contribution and interpolating negative pore water pressures (matric suction) in the soil.

The effect of matric suction on the factor of safety and reinforcement peak strains can be better understood through examination of Fig. 7, where the factor of safety and reinforcement peak strains are plotted as function of the average of matric suction measured by all the tensiometers installed in the model. From this plot, the factors of safety increased linearly with matric suction and a better stability could be noted with the time.

No significant changes in measured values of peak strains with matric suction could be evidenced, and significantly small levels of strains were noticed. Therefore, small forces were mobilized by reinforcement, and, possibly, this structure would be

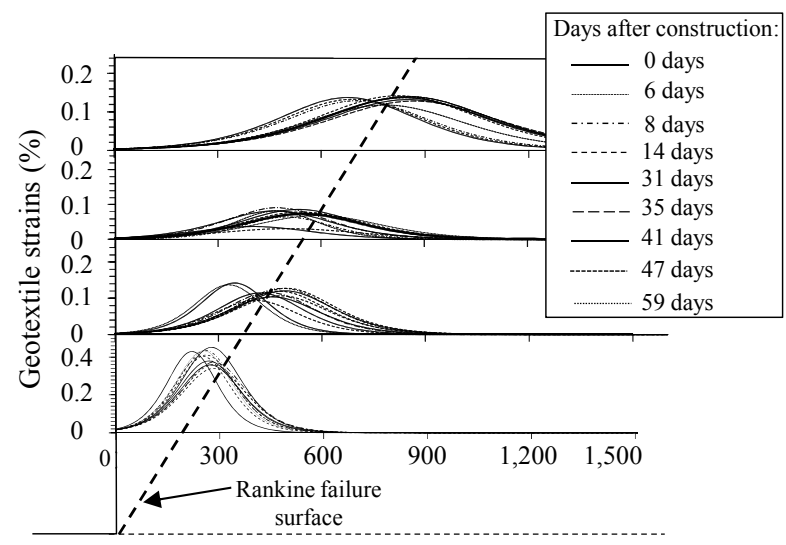

Distance from the face $(\mathrm{mm})$

Fig. 6 Distribution of strains.

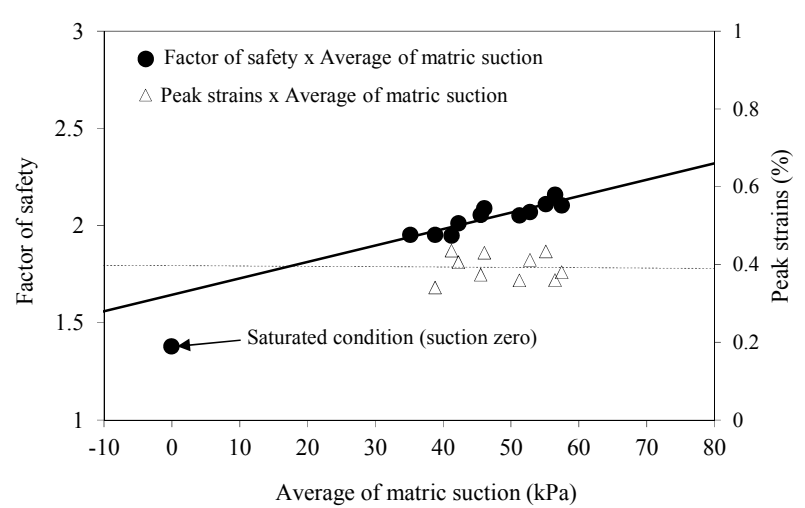

Fig. 7 Limit equilibrium analyses: effect of matric suction on factors of safety and reinforcement peak strains. 


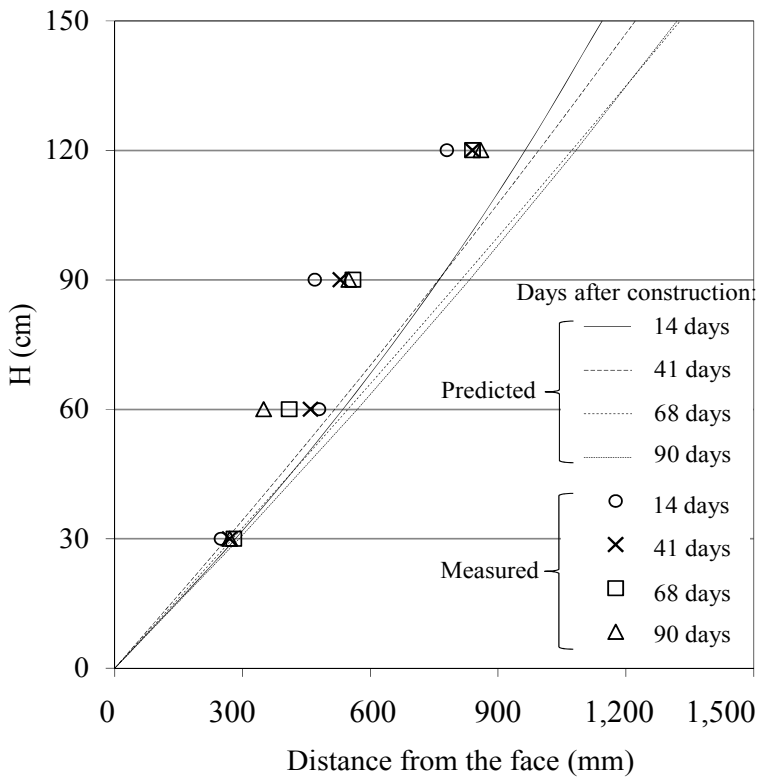

Fig 8 Slip surfaces from equilibrium limit analyses in different times.

stable even without reinforcements. In this case, reinforcements perform purely the constructability function.

Fig. 8 summarizes the slip surfaces obtained from limit equilibrium analyses inputting matric suction values. This analysis was conducted in order to compare failure surface location from measured peak strains and predicted slip surface.

Rankine failure surface (Fig. 6) showed better agreement than a circular slip surface from limit equilibrium analyses, even though factors of safety using Rankine stress state are much more conservative. Additionally, no influence of matric suction was observed on potential slip surface shapes, nor failure surfaces from measured strains.

\section{Conclusions}

The following conclusions can be drawn from the analysis of the data collected as part of this investigation:

(1) Significantly small internal displacements and reinforcement strains illustrated the positive effect of matric suction on the wall's performance;

(2) Although the matric suction increased with time, no reinforcement retraction was observed. Still, no changes on peak strains with time were noted in this study. Thus, creep strains potentials seem to be minimized by the soil matric suction, even though creep occurs over a significantly longer period than that exploited in this study;

(3) Limit equilibrium analyses have shown the increase of factor of safety with matric suction. The relationship between reinforcement peak strains with increasing factor of safety was horizontally linear, which means no changes of strains with matric suction;

(4) Small forces were mobilized by reinforcement, and, possibly, this structure would be stable even without reinforcements. In this case, reinforcements served the function of "internal drainage" which supports the work by Wayne and Wilcosky [9].

Therefore, the structure have proved to work significantly well under unsaturated condition due to the increase of soil stiffness. As a result, small forces are transmitted to the reinforcements and low strength material can be adopted. Restriction of wetting front by means of an internal drainage system and/or water barriers, and the use of unsaturated poorly draining soils, can be an economical alternative for retaining walls or reinforced slopes.

\section{References}

[1] V. Elias, B.R. Christopher, Mechanically Stabilized Earth Walls and Reinforced Soil Slopes Design and Construction Guidelines, FHWA (Federal Highway Administration), FHWA-SA-96-071, Washington, DC, 2010, p. 371.

[2] Standard Specifications for Highway Bridges, 17th ed., AASHTO (American Association of State Highway and Transportation Officials), 2002.

[3] C. Yoo, H.Y. Jung. Case history of geosynthetic reinforced segmental retaining wall failure, Journal of Geotechnical and Geoenvironmental Engineering 132 (12) (2006) 1538-1548.

[4] J.S. Fowze, D.T. Bergado, S. Soralump, M. Voottipreux, Rain-triggered landslides hazards and mitigation measures in Thailand: From research to practice, Geotextile and Geomembranes 30 (1) (2012) 50-64.

[5] C.N. Khoury, G.A. Miller, K. Hatami, Unsaturated soil-geotextile interface behavior, Geotextile and 
Geomembranes 29 (2010) 17-28.

[6] M. Ehrlich, D. Vidal., P.A. Carvalho, Performance of two geotextile reinforced soil slopes, in: Proceedings of International Symposium on Recent Developments in Soil and Pavement Mechanics, 1997, pp. 415-420.

[7] F.H.M. Portelinha, B.S. Bueno, J.G. Zornberg, Performance of nonwoven geotextiles reinforced soil walls under wetting conditions: Laboratory and field investigation, Geosynthetics International 20 (2) 90-104.

[8] R.M. Koerner, T.Y. Soong, Geosynthetic reinforced segmental retaining walls, Geotextiles and Geomembranes 19 (6) (2001) 359-386.

[9] M.H. Wayne, E. Wilcosky, An innovative use of a nonwoven geotextile in the repair of Pennsylvania State Route 54, Geotechnical Fabrics Report 14 (7) (1996) 26-29.

[10] D.V. Raisinghani, B.V.S. Viswanadham, Evaluation of permeability characteristics of a geosynthetic-reinforced soil through laboratory tests, Geotextile and Geomembranes 28 (6) (2010) 579-588.
[11] D.V. Raisinghani, B.V.S. Viswanadham, Centrifuge model study on low permeable slope reinforced by hybrid geosynthetics, Geotextile and Geomembranes 28 (6) (2011) 579-588.

[12] J.G. Zornberg, F. Arriaga, Strain distribution within geosynthetic-reinforced slopes, Journal of Geotechnical and Geoenvironmental Engineering 129 (1) (2003) 32-34.

[13] J.G. Zornberg, B.R. Christopher, J.K. Mitchell, Performance of a geotextile reinforced slope using decomposed granite as backfill material, in: Proceedings of Second Brazilan Simposium on Geosynthetics Applications, São Paulo, 1995, pp. 19-29.

[14] A. McGown., K.Z. Andrawes, M.H. Kabir, Load-extension testing of geotextiles confined in-soil, in: Proceedings of International Conference on Geotextiles, USA, 1982, pp. 793-798.

[15] S.G. Wright, UTEXAS3: A Computer Program for Slope Stability Analyses Calculation, Shinoak Software, Austin, Texas, 1990. 